\title{
CRISPR as a driving force: the Model T of biotechnology
}

\author{
Carlos Mariscal $^{1}$ (D) Angel Petropanagos ${ }^{2}$
}

(C) Monash University 2016

\begin{abstract}
The CRISPR system for gene editing can break, repair, and replace targeted sections of DNA. Although CRISPR gene editing has important therapeutic potential, it raises several ethical concerns. Some bioethicists worry CRISPR is a prelude to a dystopian future, while others maintain it should not be feared because it is analogous to past biotechnologies. In the scientific literature, CRISPR is often discussed as a revolutionary technology. In this paper we unpack the framing of CRISPR as a revolutionary technology and contrast it with framing it as a valuethreatening biotechnology or business-as-usual. By drawing on a comparison between CRISPR and the Ford Model T, we argue CRISPR is revolutionary as a product, process, and as a force for social change. This characterization of CRISPR offers important conceptual clarity to the existing debates surrounding CRISPR. In particular, conceptualizing CRISPR as a revolutionary technology structures regulatory goals with respect to this new technology. Revolutionary technologies have characteristic patterns of implementation, entrenchment, and social impact. As such, early identification of technologies as revolutionary may help construct more nuanced and effective ethical frameworks for public policy.
\end{abstract}

Keywords Biotechnology · CRISPR · CRISPR/Cas9 · Gene editing · Gene therapy $\cdot$ Revolutionary technology

Carlos Mariscal

carlos@philbio.org

1 Department of Philosophy, University of Nevada, Reno, Reno, NV, USA

2 Novel Tech Ethics, Department of Medicine, Dalhousie University, Halifax, NS, Canada 


\section{Introduction: the CRISPR controversy}

Although genome editing itself is not new, the CRISPR system ${ }^{1}$ for gene editing has elicited renewed excitement and fear over medical, ethical, and social implications of this technology. In particular, in early 2015, the application of CRISPR on nonviable human embryos sparked heated public debates regarding the appropriate uses of gene editing (Liang et al. 2015; Baltimore et al. 2015a, b). Discussions about CRISPR in recent months indicate an underlying disagreement among researchers about the ethical and social implications of this technology. Some researchers worry that CRISPR will lead to designer babies and eugenics, proliferate social injustice, and risk disastrous changes to society and the environment (Lanphier et al. 2015; Ledford 2015). These critics appeal to the long history of failed human interventions as evidence that a tool with the breadth and power of CRISPR should be subject to intense scrutiny and regulation. Others seem to characterize CRISPR as "just another biotechnology' (Harris 2016). These researchers downplay the concerns about CRISPR research by analogy to once-feared biotechnologies, like in vitro fertilization and cloning. These researchers argue the ethical concerns about CRISPR are overblown because they are not new or are unlikely to come to pass (Morange 2015). Instead, they emphasize the positive therapeutic potential of CRISPR technology.

There are advantages and disadvantages to adopting either of these ethical framings for CRISPR gene editing. For example, emphasizing the possible dangers of CRISPR gene editing may help slow or eliminate dangerous practices, but it might also hinder beneficial applications. Alternatively, the 'just another biotechnology' approach may open the door for beneficial CRISPR research, but ignore potential bad consequences of the technology as well as the ways in which older biotechnologies remain ethically controversial. Each approach foregrounds distinctive issues and serves to shift the burden of proof to its deniers. The characterization of CRISPR matters insofar as framing the ethical analyses also shapes the development of this emerging technology.

There is an third way of framing of the CRISPR system. Several scientists have referred to CRISPR as 'groundbreaking,' 'revolutionary,' and 'disruptive' (Barrangou 2014; Zhang and Zhou 2014; Kennedy and Cullen 2015; Ledford 2015; Sontheimer and Barrangou 2015). Henry T. Greely recently characterized the CRISPR system as 'the Model T of genetics' (Specter 2015). Framing the CRISPR system as revolutionary presents an interesting alternative to the dystopia/businessas-usual dichotomy. Revolutionary technologies follow similar patterns of implementation, entrenchment, and social impact while being a priori unpredictable in the specifics of their consequences.

Science, Technology, and Society scholar David Collingridge poses a dilemma for new technologies. Before the technology is developed and implemented, there is

\footnotetext{
${ }^{1}$ CRISPR (clustered regularly interspaced short palindromic repeats) is a nucleic acid construct, Cas is one of the associated families of enzymes (specifically nucleases), which can sever DNA strands in desired locations, triggering cell-repair mechanisms. By providing replacement DNA to the cell, researchers can effectively 'edit' genetic material. Unless the context calls for specificity, we will use 'the CRISPR system' to refer to the enzyme-mediated gene-editing biotechnology.
} 
an information problem, as the potential impact cannot be easily predicted. But after the technology becomes entrenched, society faces a power problem, as controlled change becomes difficult (Collingridge 1980). If history is a guide, revolutionary technologies have only a small window of time in which regulators can avert potential problems in the transition from fragile-ideas-with-unknown-consequences to known-and-difficult-to-regulate-industries (Collingridge 1980; Moor 2005). The full spectrum of social and ethical implications of a new technology are unknowable if each aspect of a new technology is addressed independently.

In this paper, we argue the CRISPR system is revolutionary and ought to be conceptualized as such within media and research communities. Framing this technology as such offers an important lens from which to assess the nuanced ethical and social implications of CRISPR. In particular, the recognition of the CRISPR system as a revolutionary technology will serve to emphasize the complex and far-reaching potential of genome editing. We begin with a brief description of revolutionary technologies to illustrate how they differ from normal technologies. We then build on Greely's comparison of the CRISPR system and the Model T in order to illustrate how this new gene editing system is revolutionary. We explore three distinct ways of understanding the CRISPR system as revolutionary, namely: as a product with great versatility, as a speedy and affordable process, and as a social force of great impact. Together, these three points of comparison show that CRISPR gene editing is most fruitfully understood as revolutionary. We conclude by arguing the CRISPR-as-revolutionary framing can guide inquiry and support ethical deliberation and public policy with respect to CRISPR.

\section{Background: CRISPR as a revolutionary biotechnology}

A technological revolution can be defined as a quick change brought about by the introduction of a new technology or a way of making prior technologies simpler, accessible, or more affordable (Bostrom 2007, p. 129; Christenson 1997; Moor 2005, p. 114). Recent history is filled with such innovations: computers, cellular phones, and social media are three recent examples out of hundreds. Such innovations are distinctive with respect to their negative consequences for established markets and value systems (Christenson 1997). The emergence of these technologies may also raise policy vacuums in which policies (laws, rules, and customs) developed under earlier paradigms no longer apply in the new situations that occur as a result of adopting these technologies (Moor 2005, p. 115).

It may help to see how the CRISPR system fits into this characterization. CRISPR technology, in many areas of science, is already entrenched as the go-to method for gene editing because of its versatility, cost, and ease. In these areas, we face a new technology's power problem as introducing effective new regulations would be difficult or ineffective. Consider the fact that when similar regulations were introduced in the United States to curtail research on embryonic stem cells, several top researchers emigrated to Singapore and other countries rather than cease their work (Colman 2008; Dhar and Hsi-en Ho 2009). 
In other areas in which CRISPR is important, we are entering a new frontier that is still being explored. This is especially true for more speculative uses of CRISPR, such as de-extinction, controlled extinction, and encryption of hidden messages in living tissue (see Charo and Greely 2015). Here we face the information problem for new technologies, as we know relatively little about what new uses CRISPR may have, how they could be implemented, or how they may impact society. The harnessing of genetic changes will be guided by political, commercial, scientific, and personal interests. It is impossible to know exactly how CRISPR will change the world, but history teaches us the effects of revolutionary technologies will be complex and far-reaching. If this is truly a revolutionary technology, ethicists and regulators may soon confront wide, commercial, industrial, and personal use (Moor 2005).

CRISPR is of particular interest because of its speed, ease, and versatility of use. Many researchers are optimistic about the potential therapeutic benefits of CRISPR technology and anticipate that it will eventually be lead to treatments of various human ailments, including AIDS, malaria, and cancer (Specter 2015). That such wide-ranging therapies are being considered is evidence of the CRISPR system's revolutionary potential. But careful attention to the history of prior revolutionary technologies ought to make us give pause; the benefit of hindsight brings into relief what is likely to be quite opaque to people at the time.

It can occasionally be ambiguous whether the revolutionary technology is understood as the product itself, how the product is made, or its impact. We distinguish between these three different understandings. We will first present Greely's example of the Model T as a product (car), a process (the moving assembly line), and by its social uptake (by inspiring a range of important social changes). Next, we will see how these map onto the CRISPR system. We consider it as a kind of revolutionary product (gene editing), as a process (its versatility and efficiency), and finish by considering its social uptake. Although we consider each separately, each of these conceptions overlaps and influences the others to a great extent.

\section{The Model $T$ revolution}

What made the Model $\mathrm{T}$ so famous and influential was not that it was a particularly good car; in fact, it had a number of design problems. For example, it never had turn signals and it needed to go up steep hills in reverse (Duncan 2011, p. 82). Rather, one sense in which the Model $\mathrm{T}$ is revolutionary is as an exemplary instance of $a$ revolutionary product: cars themselves. Womack et al. (1990) describe the automobile as the machine that changed the world. Automobiles are versatile. They offer improvements in the speed and capacity of any number of tasks compared to walking or riding. Cars connect people and products across great distances, dramatically shortening travel times. Originally viewed as a luxury item (Duncan 2011, p. 9), the automobile brought a new source of social status, pleasure, entertainment, and, in some cases, personal identity.

The Model $\mathrm{T}$ was the result of a truly revolutionary process: Henry Ford's careful attention to production flow and further development of the most important 
innovations in the history of manufacturing: interchangeable parts, vertical integration, and the moving assembly line (Williams et al. 1992; Alizon et al. 2009). Earlier cars were designed and assembled by skilled craftspersons, so relatively few were produced in the 20 years before Ford began his operation in 1908 (Duncan 2011). Assembly lines and interchangeable parts had been in use in various industries for decades, and were in fact, also used by Oldsmobile, a competitor. But Ford is known for introducing a moving assembly line, which would bring the vehicle to workers, octupling their production rate. This meant that thousands and, eventually, tens of thousands of cars could be produced-driving the cost of cars down to the equivalent of a worker's few months' salary, $\$ 950$ initially, but eventually as low as $\$ 360$ (Williams et al. 1992). Ford's triumphant development of the moving assembly line eventually became incorporated in many other industries. There is a direct link between the process perfected by Ford in the Model $\mathrm{T}$ and the unparalleled productivity of the United States in the middle part of the 20th century. This is especially evident in the country's unparalleled production of wartime materiel and factory-raised food.

Finally, we can consider the Model $\mathrm{T}$ with respect to its revolutionary societal impact. Although cars had existed for decades before the popularization of Model T, walking and riding horses (or horse-drawn carriages) continued to be the main modes of transportation. So even if cars were revolutionary as technology, they weren't revolutionary in terms of actual impact on people or the world. Ford is known for manufacturing 15 million Model Ts in 20 years, more than all other American carmakers combined (Alizon et al. 2009). At one point, nearly one in every two cars sold in the world was a Model T. The Model T changed the way that people got around. The Model $\mathrm{T}$ revolution had an enormous impact on individual and family life. The affordability of the car meant that people could travel farther, quicker, and more easily. This made doing errands, getting to work, and visiting friends or family much easier. It also meant that families could live farther away from work or the city. Paradoxically, the increased ease in transportation led to a more sedentary lifestyle.

The Model $\mathrm{T}$ also had extreme economic consequences. To combat costly employee turnover and forestall unionization, Henry Ford opted to pay his workers an unparalleled $\$ 5$ a day (Womack et al. 1990). Many historians now view this as the beginning of the American middle class (Ingrassia 2008). As a result of the Model T's popularization of automobiles, entire areas of the economy were created while others were devastated. The jobs cars took away were balanced by the jobs created in new industries: hotels boomed as people traveled beyond their usual haunts, new accessory markets flourished, and there arose an international demand for rubber, steel, and oil (Sturgeon and Florida 2000). These had a profound, direct, and lasting impact on nations in South America and the Middle East. Cars became such a central part of the American identity that, 100 years later when American automobile manufacturers were about to go bankrupt, the U.S. government gave the industry billions of dollars to keep their doors open. In its peak, automobile manufacturing in America was an economic powerhouse, making cities such as Detroit enormously wealthy and influential. Due to technical constraints in shipping vehicles, the car could be produced in Detroit, but had to be assembled in dozens of 
other cities, thus bringing an economic boost to a number of areas in the U.S. and a number of other countries worldwide (Sturgeon and Florida 2000).

The Model T was advertised as the "Universal Car" and used as everything from simple transportation to agricultural machinery (Kline and Pinch 1996, p. 785). For example, aftermarket kits were created in order to transform Model Ts into sources of power to run machinery and haul farm supplies. The Model T contributed to the mechanization of farming. It also allowed for the easier and quicker movement of agricultural goods between the farm and cities. The Model $\mathrm{T}$ also had a massive environmental impact. Lead was introduced in the 1920s to improve performance, which acutely poisoned the workers who produced it and settled into the bodies of every organism on the planet (Nriagu 1990). Smoke from car exhaust contributed to smog problems in cities around the world. The rubber industry in South America was not only damaging to the locals, it also had a profound and permanent effect on the landscape of the continent (Sturgeon and Florida 2000). Parking lots were built to house cars and roads were built to ease interstate and international travel. These lots and roads literally changed the landscape of the planet, interrupting local flora and fauna.

In the next section, we similarly consider the CRISPR system as revolutionary with regard to it as a product, a process, and its societal impact. In each, we explore the ways this technology has and will continue to change the landscape of research, agriculture, medicine, ecosystems, personal use, and military or government use.

\section{The CRISPR revolution}

\subsection{A revolutionary product}

Sometimes the CRISPR system is understood as merely a particularly effective instance of gene editing, and the edited gene is what is considered revolutionary. Gene editing is not new. Gene editing can be used to alter the genetic material in any organism at any stage of development: somatic (body) cells to alter individual organisms or germ (reproductive) cells to alter the genetic material of future generations (Carroll 2014).

Because CRISPR and other techniques are able to affect any gene in any organism, the possibility of editing genes is as versatile as the living world itself. Genes edited by the CRISPR system are typically edited more accurately than those edited by alternative methods. Stem cell researcher Chad Cowan pointed out that the best result using the prior technology of TALENs was worse than the worst result using CRISPR technology (Cowan 2015). Although Liang et al. (2015) reported that "CRISPR/Cas9 could effectively cleave the endogenous $\beta$-globin gene (HBB).... [but] the efficiency of homologous recombination directed repair (HDR) of HBB was low and the edited embryos were mosaic. ... [with evidence of] untoward mutations" (p. 363).

Gene editing has a forty-year history (Friedmann and Roblin 1972), but aside from appearances in science fiction, most of the public is unaware of the actual frequency and breadth of gene editing currently in use. In research contexts, the 
disruption or removal of genetic material (knockouts) in model organisms is most familiar. By studying modified organisms that lack specific genes, scientists have been able to infer functions for large parts of genomes. One gene-editing company even boasts offering genetic knockouts of every gene in mice and rats (SigmaAldrich 2011). In addition to genetic knockouts, scientists are able to insert genes (knockins) and partially suppress genes (knockdowns). This research is merely a new approach to the long history of breeding experiments in biology. Such research has allowed an unprecedented level of understanding, prediction, and control of the genomes of all living things. For example, researchers have been able to create a living creature from synthetic parts, first accomplished with a parasitic bacterium in 2008 (Gibson et al. 2008).

Editing genes is not only important for scientific research, it has already transformed agriculture. Agriculture is often an early adopter with respect to biotechnologies (breeding, in vitro fertilization, and cloning). It is likely that the CRISPR system will be safer for use in agriculture than current techniques, which are less accurate, efficient, or scalable. In other words, researchers will be able to edit plant and animal genomes with fewer potential side effects. Researchers are now pursuing the use of gene editing to create hardier, better tasting, bigger, and allergen-free crops (Gallo and Sayre 2009). They may also use genetic engineering to modify animals for consumption. Agriculture is a fascinating test case in how the public will respond to this technology, as demonstrated by the rate of concern for genetically modified organisms (GMOs) by the lay public.

But much of the debate over edited genomes centers around issues in health care. There is as much optimism about CRISPR-based gene editing as there was for the Human Genome Project nearly two decades ago. We now know of a number of diseases and syndromes which are caused by mutations to single genes, such as Huntington's Disease. Much of the excitement about the CRISPR system centers on the perceived ease of treating such diseases or other diseases which can be treated by simple modifications, as with HIV/AIDS which relies on a single cell receptor. In some of these cases, gene editing may be able to offer simple and permanent cures. Some countries have already approved gene therapy (Peng 2005; Wilson 2005; Räty et al. 2008) and even successfully treated certain cancers using bone marrow transplantation of edited cells (Reardon 2015). We have already seen a potential therapy of a rare pancreatic disease marketed for 1,000,000 Euros (Kutter 2015). In the United States, there are currently no gene therapy products for sale, although the Center for Biologics Evaluation \& Research (CBER) has received many applications (Räty et al. 2008; FDA 2015). Likely this is due to lessons from Jesse Gelsinger, the first human to die as a result of gene therapy. Gelsinger had a severe immune response to the virally transmitted gene therapy, which resulted in the collapse of multiple organs. As a result, regulatory bodies became extremely concerned with human gene therapy and most clinical applications were delayed or canceled. In the response to this tragic situation, clinicians, scientists, internal review boards, granting agencies, and regulatory agencies developed new policies to address the concerns Gelsinger's case raised.

With the new wave of genetic therapies, critics of health care uses raise familiar concerns about inequity and disability rights, off-target effects, and permanent 
biological changes which may constitute eugenics. Such concerns did not come to pass with earlier biotechnologies, such as IVF, as advocates of the businessas-usual framing point out (Harris 2016). If anything, IVF babies are at a greater risk for some ailments relative to the general population (Davies et al. 2012). CRISPR advocates also point out that CRISPR researchers take issues like offtarget effects very seriously and continue to try address them (Zhang and Zhou 2014). Some scientists working on CRISPR also reject the characterization of gene editing as an irreversible intervention (Specter 2015). Recent research on evolutionary and developmental biology ('evo-devo') has emphasized that much of biology occurs apart from (and interacts with) genetics (see Carroll 2008). So, although genes edited early in development will produce more entrenched changes in an organism, most replaced genes can simply be reversed if they show themselves to be hazardous. For example, the vast majority of biological sex characteristics are produced during development, so gene therapy of adults is unlikely to greatly improve medical gender reassignment. Importantly, all sides acknowledge the massive changes we have already seen with gene-editing technologies and the CRISPR system is the latest and potentially the most impactful.

\subsection{A revolutionary process}

The CRISPR system is another gene-editing technology, but it is not just another technology. Early technologies took $2-3$ years and $\$ 100,000$ to develop single organisms with single desired modification (Yeadon 2015). Zinc finger nucleases (ZFNs), an early gene-editing technique, are $\sim 30$ amino acids long and bind to 3-base pair triplets (Kennedy and Cullen 2015). ZFNs, when bound to other molecules, can edit DNA with very little risk of off-target effects, but they are not able to bind to all 3 base pair triplet combinations, are expensive, difficult, and a proprietary product (Sander et al. 2011; Kennedy and Cullen 2015; Yeadon 2015). More recent biotechnologies like transcription activator-like effector nucleases (TALENs) are cheaper and more effective, targeting individual bases rather than longer sequences. Recently, TALENs were used to effectively treat a young girl with Leukaemia (Reardon 2015). But each of these technologies is still more difficult to engineer, less accurate, and less effective than the CRISPR system.

The CRISPR system is composed of a guide RNA linked to an enzyme (typically Cas9, though many others exist). Previous gene-editing technologies consist of proteins specifically developed to target nucleotides or sets of nucleotides. Because the Cas9 enzyme does not change from use to use, only the 20-nucleotide guide RNA needs to be produced rather than the much larger, delicate, and cumbersometo-produce proteins used in ZFNs and TALENs. The fact that the associated RNA is easily interchangeable makes the DNA targeting much easier and faster. In fact, there are companies that can quickly deliver any requested RNA sequence, making the whole process much simpler (Specter 2015). By making the process less laborious and more efficient, CRISPR/Cas allows a wide variety of scientists to edit genomes. 
As a gene-editing tool, the CRISPR system burst onto the scene in 2013 (Mali et al. 2013; Jinek et al. 2013; Hwang et al. 2013; Jiang et al. 2013; Cong et al. 2013; DiCarlo et al. 2013; Ding et al. 2013; Friedland et al. 2013; Gratz et al. 2013; Li et al. 2013a, b, c; Wang et al. 2013; Nekrasov et al. 2013). Just last year, it attracted significant public attention when researchers attempted to modify 'non-viable' human embryos in order to edit a gene responsible for $\beta$-thalassaemia, a potentially fatal blood disorder (Liang et al. 2015). The controversy that developed afterward has been fierce. CRISPR doubters worry research is proceeding at a quicker pace than ethical deliberation (Hosman 2015).

There are now over two hundred patent applications which mention CRISPR and at least four CRISPR-based biotechnology companies have opened, raising tens of millions of dollars each (Ledford 2015). Given the availability, versatility, and accessibility of the CRISPR system, it has spread quickly in the scientific community, with tens of thousands of citations over hundreds of papers in only the past few years. As a comparison, within a year of the first gene edited by CRISPR/ Cas, it became subject to more scientific articles than ZFNs and TALENs combined. CRISPR technology has become so central in many areas of science that many scientists working with the CRISPR system already view it as the new gold standard for gene editing.

\subsection{Revolutionary social impact}

We have discussed how gene editing could treat any number of medical conditions, considered some of the potential impacts on agriculture, and also discussed how the CRISPR system has already become the gold standard in many areas of science. Given the cost, speed, and versatility of CRISPR technology, many believe it will impact many number of other areas of life. There are now companies marketing CRISPR kits to the public. These kits allow people to genetically modify bacteria to glow or change color (Chung 2015). Because biology is omnipresent in life, it is possible for lay use of CRISPR technology to influence any number of areas of dayto-day life, disrupting current markets even as it opens new ones. Intuitively, we would expect the greatest impact to be in jobs that currently take long periods of time to develop biological results: such as animal breeding, plant horticulture, conservation of species, removal of pests, and the production of cultured foods such as dairy and alcohol.

More broadly, Esvelt et al. (2014) suggest that CRISPR can be selectively used to alter the traits and population size of organisms within ecosystems. Gene editing might be used to control populations of species ecologists may call 'invasive,' such as rats, cane toads, or lionfish. Esvelt et al. suggest that, unlike chemical or biocontrol methods, CRISPR would be able to target a particular species and eradicate it. For example, Anopheles stephensi mosquitoes carry a parasite that is responsible for malaria, a disease that causes the deaths of over 500,000 people every year (Esvelt et al. 2014). One proposal, which has now been enacted by researchers (Gantz et al. 2015), involves creating a gene drive in mosquitoes that could kill the parasite that infects mosquitoes and causes the spread of malaria. Within a relatively short amount of time, it is conjectured that they will be able to 
drive the malaria-causing parasite extinct. This approach would be quick, effective, and less toxic than chemical alternatives, which have been getting less effective as mosquitos build a tolerance to them (Esvelt et al. 2014). Such an intervention could save the lives of millions of people, mostly children under 5 in developing nations. CRISPR could also be used to promote more sustainable agriculture by controlling insect pests and reverse herbicide resistance in weeds. Critics maintain the modification of organisms in open ecosystems is unwise and potentially dangerous (Ledford 2015). Some are skeptical about the notion of Western people making permanent interventions into the ecosystems of mostly developing countries, as the history of such interventions is plagued with horrible consequences. It is important to remember that all human interventions are necessarily value-laden. As we modify the world, we inevitably try to change it into the world as we wish to see it.

Conversely, the Long Now Project has proposed using CRISPR technology for the purposes of de-extinction (Sherkow and Greely 2013). The idea is simply that we might be able to engineer embryos with the DNA of extinct species. This might allow us to bring back such culturally significant species as the passenger pigeon, dodo, and wooly mammoth. Such endeavors are both more plausible and justifiable when they serve some environmental purpose. But this proposal has been suggested before with earlier biotechnologies, like cloning. Outside of fictional dinosaur amusement parks, it has never received uptake, likely due to technical limitations on the range of organisms for which this would be feasible. Regardless of the mechanism, critics challenge that resources are better used for the preservation of current species (Zimmer 2013). They also caution against reintroducing extinct species, especially when the relevant ecosystems have changed significantly: species may simply go extinct again or even turn out to be invasive in their own former environments! Regardless, future generations may see some limited use of de-extinction or gene-editing-related species preservations, especially in environments in which human activity has recently driven a local species to extinction. The ethical features of each scenario may differ, and policy decisions are likely to require input from CRISPR experts, experts in ecology and evolution, policy experts, local stakeholders, and ethicists.

We can imagine uses for CRISPR will only increase in frequency and creativity (see Charo and Greely 2015), perhaps even involved in personal use. In our lifetime, we may see foods or pets customized and marketed to suit individual's whims. Researchers have already proposed using CRISPR to modify pigs to develop human-compatible organs (Yang et al. 2015). CRISPR could also be used to genetically modify domestic pets to be more appealing to humans. For example, Chinese researchers recently used gene editing to create "micro pigs" that would be sold as pets (Li et al. 2014; Larson 2015). Their institute plans to sell the micro pigs for US $\$ 1600$. Customers would be able to custom order their pet micro pig with a coat color and pattern of their choosing (Lewis 2015).

If any of these proposals materialize, there will be widespread political ramifications. We have already seen this in the recent, international calls for a moratorium on human germline editing, which may be perceived as targeting China and the Chinese researchers who crossed this new frontier. China allowed gene 
therapies during a decade in which many other countries avoided their clinical use, resulting in last year's use of CRISPR on human embryos (Liang et al. 2015). In a recent workshop on gene editing, Qi Zhou of the Chinese Academy of Sciences was questioned at length about the nature of regulation in China. Many in the audience were concerned to discover that regulations in China are unenforced (Zhou 2015). As more uses for this technology arise and other nations become early adopters, international agreements will become even more difficult to agree upon or enforce. This will be especially difficult if new innovations can be monetized and result in economic or political power for individual countries.

The use of CRISPR for military purposes is harder to assess and can easily lead to paranoia. Thankfully, there are some reasonable conclusions to draw. Due to the expertise needed to use the technology, it is unlikely, for instance, that the near future will see CRISPR used for nefarious purposes in the hands of poorly funded extremist groups. Nevertheless, some might fear the uses foreign governments may see for CRISPR. While it is easy to imagine CRISPR being used to create a 'super bug'gene editing has already been used to recreate a live polio virus (Specter 2015) such uses are impractical from a military perspective. Biological weapons are much less predictable than traditional weapons because reproduction does not respect national boundaries and evolution is a powerful, unpredictable, and largely uncontrollable force (Mariscal 2015). While gene editing is unlikely to be of strategic use, we should always remain aware of the potential for desperate, incompetent, or terrorist acts using such a technology. We do not expect gene editing to be used to enhance humans in the military, as more reliable and stable conventional technologies are already replacing humans on the battlefield. We might, however, see CRISPR-based therapies used for battlefield injuries. Among the more intriguing and plausible options are the use of CRISPR to label organisms or otherwise encode unbreakable, untraceable messages in the DNA of living tissue (Brunet 2016), though one may doubt the frequency in which such techniques may be necessary. The detection of edited genes will be essential in such a scenario, though methods for doing it quickly and reliably may still be far off in the future.

\section{Lessons from hindsight}

What do we learn from the Model T? How would the world have looked differently if we thought about the far and wide-reaching implications of revolutionary technologies as they were first introduced? Likely, the most important action would be a continued, critical evaluation of the technology to address emerging problems before they become entrenched. Rather than emerging in the late 1960s, suppose a Taft or Wilson administration created a Department of Transportation and imbued it with regulatory powers. Such a department would likely have foreseen some problems early on: traffic and city planning, collisions, car safety, and possibly the toxicity of lead in gasoline. Other problems may have been missed-air pollution, possibly climate change, and possibly oil demand as a driver of geopolitical strife. Such a department would also have focused on issues we no longer regard as problematic - the fate of the horse industry, the shift away from widespread public 
use of railroads, and the cost of redesigning cities and infrastructure. Nevertheless, it would have engaged with new uses and discoveries of automobiles as they emerged, rather than decades later after many corporations had entrenched interests in maintaining the status quo.

A similar department or organization with respect to gene editing may have mixed outcomes. In general, it could regulate the types of research or clinical applications of CRISPR that are permissible. Such a department could also help to ensure the just and equitable distribution of the benefits resulting from CRISPR and enact barriers or restrictions on the commercialization of this technology. Currently, a number of organizations are paying close attention to CRISPR, including scientific organizations like the U.S. and Chinese National Academies of Science, media like the New Yorker (Specter 2015), regulatory agencies like the FDA's Center for Biologics Evaluation \& Research (FDA 2015), and watchdog groups like the International Center for Technology Assessment. There is no centralized body to assess such technologies and there is likely a wide range of applications of CRISPR work that may fall in a 'regulatory vacuum' (Moor 2005). Recently, the US Department of Agriculture (USDA) declined to regulate CRISPR-modified mushrooms due to a technical loophole (Waltz 2016). Under USDA regulations, GMOs must contain foreign DNA from plant 'pests.' While such DNA was needed for genetically modifying organisms when the regulations were written in the 1980s, it is no longer necessary. The USDA plans to overhaul its regulations over the next decade and many goods will likely make it to the market in the meantime. The environmental, social, economic, and ethical implications of using CRISPR on animal and other living cells cannot be bound by national borders. The globalized nature of science and technology necessitates an international approach to CRISPR technology, so international cooperation is needed for any ethical regulation and provision of CRISPR.

As we remarked in the introduction, revolutions have unpredictable consequences even as they have predictable patterns of disruption and entrenchment. They rarely result in the best or worst-case scenarios envisioned at the time. Nevertheless, it is likely society will mishandle some of the effects of CRISPR. We know from the history of revolutionary technologies like the Model $\mathrm{T}$ that we will not know a technology's social and ethical implications if we address each issue independently. Consequently, an intellectually honest, historically informed approach suggests we should develop a continuous engagement with the technology, ideally in the form of a multidisciplinary, internationally respected body with some amount of regulatory oversight.

\section{Conclusion: future directions}

The inevitable normalization of CRISPR gene editing will have far reaching implications for all areas of life. CRISPR system is a revolutionary biotechnology with a range of impact broader than any other biotechnology in recent memory. Recognizing this fact will facilitate a broad range of ethical inquiry and caution in what is best described as a social experiment. Like the Model $\mathrm{T}$ was in its time, 
CRISPR is easier, more accessible, and more versatile than the technologies it is disrupting. This understanding of CRISPR reveals the need for continuous, interdisciplinary, and international oversight. This should consist of experts in the relevant areas (synthetic biologists, medical doctors, ecologists, economists, ethicists, public policy experts, etc.) as well as the stakeholders in any proposed interventions (scientific organizations, pharmaceutical companies, disability rights advocates, environmentalists, the public, etc.). While this may be difficult now, it will become impossible as the technology becomes socially entrenched. As such, it is important for scientists, media, and policy-makers to move forward pushing for as much of a unified front as possible.

The way we conceptually frame tools and technologies can hinder or support ethical inquiry. When we view them as foreshadowing grim dystopias, we foreground stronger regulatory oversight and an abandonment of current lines of inquiry. When we view them as business-as-usual, we assume regulators should not reevaluate the technology or that negative consequences have, are, or will be adequately addressed. Each framework alienates advocates of the other. Each side may view the other as naïve and judge the other position based on its loudest, least thoughtful advocates. Furthermore, with CRISPR, both approaches overemphasize certain uses: human evolution and equity versus medical therapies and scientific understanding. It is our hope that taking the CRISPR-as-revolutionary framework seriously will highlight the promise and peril of this biotechnology without overemphasizing either.

Hindsight is a privilege. Looking back at the Model $\mathrm{T}$ we are reminded of both the benefits and harms of technological revolutions. CRISPR has myriad applications: scientific discovery, medicine, agriculture, ecology, commerce, military, etc. But any human intervention in the world reflects our understanding of it as well as our underlying values. Because of the unprecedented versatility, ease, and speed of this technique, there is a need for ongoing public debate on the future direction of CRISPR research and applications. Insofar as CRISPR is a revolutionary technology, the ethical development, implementation, and provision of CRISPR requires early regulatory oversight and attention to its far-reaching global implications.

Acknowledgments Funding in support of this research was provided by the Canada Research Chair in Bioethics and Philosophy on "Impact Ethics: Making a Difference" and the Natural Sciences and Engineering Research Council of Canada grant no. GLDSU/447989. We thank the team at Novel Tech Ethics, Dalhousie University for their feedback on earlier drafts.

\section{References}

Alizon, F., S.B. Shooter, and T.W. Simpson. 2009. Henry Ford and the Model T: Lessons for product platforming and mass customization. Design Studies 30(5): 588-605.

Baltimore, D., F. Baylis, P. Berg, G.Q. Daley, J.A. Doudna, E.S. Lander, R. Lovell-Badge, P. Ossorio, D. Pei, A. Thrasher, E. Winnacker, and Q. Zhou. 2015a. On human gene editing: International summit statement. http://www8.nationalacademies.org/onpinews/newsitem.aspx?RecordID=12032015a (Press Release).

Baltimore, D., P. Berg, M. Botchan, D. Carroll, R.A. Charo, G. Church, J.E. Corn, G.Q. Daley, J.A. Doudna, M. Fenner, H.T. Greely, M. Jinek, S.G. Martin, E. Perhoet, J. Puck, S.H. Sternberg, J.S. 
Weissman, and K.R. Yamamoto. 2015b. A prudent path forward for genomic engineering and germline gene modification. Science 348(6230): 36-38.

Barrangou, R. 2014. Cas9 targeting and the CRISPR revolution. Science 344(6185): 707-708.

Bostrom, N. 2007. Technological revolution: Ethics and policy in the dark. In Nanoscale: Issues and perspectives for the nano century, ed. M. Nigel, S. de Cameron, and E.M. Mitchell, 129-152. New York: Wiley.

Brunet, T.D.P. 2016. Aims and methods of biosteganography. Journal of Biotechnology 226: 56-64.

Carroll, D. 2014. Genome engineering with targetable nucleases. Annual Review of Biochemistry 83: 409-439.

Carroll, S.B. 2008. Evo-devo and an expanding evolutionary synthesis: a genetic theory of morphological evolution. Cell 134(1): 25-36.

Charo, R.A., and H.T. Greely. 2015. CRISPR critters and CRISPR cracks. The American Journal of Bioethics 15(12): 11-17.

Christenson, C. 1997. The innovator's dilemma. Cambridge, MA: Harvard Business School Press.

Chung, E. 2015. Synbiota biohacking kits let you do genetic engineering at home. CBC News, October 15. http://www.cbc.ca/news/technology/biohacking-diy-bio-1.3252735. Retrieved November 4, 2015.

Collingridge, D. 1980. The social control of technology. London: Pinter.

Colman, A. 2008. Stem cell research in Singapore. Cell 132(4): 519-521.

Cong, L., F.A. Ran, D. Cox, S. Lin, R. Barretto, N. Habib, P.D. Hsu, et al. 2013. Multiplex genome engineering using CRISPR/Cas systems. Science 339(6121): 819-823.

Cowan, C. 2015. Measuring off-target events, efficiency, and utility. Presentation, information-gathering meeting for the planning committee organizing the international summit on human gene editing, October 5, Washington, DC.

Davies, M.J., V.M. Moore, K.J. Willson, P. Van Essen, K. Priest, H. Scott, E.A. Haan, and A. Chan. 2012. Reproductive technologies and the risk of birth defects. New England Journal of Medicine 366(19): 1803-1813.

Dhar, D., and J. Hsi-en Ho. 2009. Stem cell research policies around the world. The Yale Journal of Biology and Medicine 82(3): 113-115.

DiCarlo, J.E., J.E. Norville, P. Mali, X. Rios, J. Aach, and G.M. Church. 2013. Genome engineering in Saccharomyces cerevisiae using CRISPR-Cas systems. Nucleic Acids Research 41(7): 4336-4343.

Ding, Q., S.N. Regan, Y. Xia, L.A. Oostrom, C.A. Cowan, and K. Musunuru. 2013. Enhanced efficiency of human pluripotent stem cell genome editing through replacing TALENs with CRISPRs. Cell Stem Cell 12(4): 393.

Duncan, J. 2011. Any colour-so long as it's black: Designing the Model T Ford 1906-1908. New Zealand: Exisle Publishing.

Esvelt, K.M., A.L. Smidler, F. Catteruccia, and G.M. Church. 2014. Concerning RNA-guided gene drives for the alteration of wild populations. Elife 3: e03401.

Friedland, A.E., Y.B. Tzur, K.M. Esvelt, M.P. Colaiácovo, G.M. Church, and J.A. Calarco. 2013. Heritable genome editing in C. elegans via a CRISPR-Cas9 system. Nature Methods 10(8): $741-743$.

Friedmann, T., and R. Roblin. 1972. Gene therapy for human genetic disease? Science 175(4025): 949-955.

Gallo, M., and R. Sayre. 2009. Removing allergens and reducing toxins from food crops. Current Opinion in Biotechnology 20(2): 191-196.

Gantz, V.M., N. Jasinskiene, O. Tatarenkova, A. Fazekas, V.A. Macias, E. Bier, and A.A. James. 2015. November 23). Highly efficient Cas9-mediated gene drive for population modification of the malaria vector mosquito Anopheles stephensi. Proceedings of the National Academy of Sciences 112(49): E6736-E6743.

Gibson, D.G., G.A. Benders, C. Andrews-Pfannkoch, E.A. Denisova, H. Baden-Tillson, J. Zaveri, T.B. Stockwell, et al. 2008. Complete chemical synthesis, assembly, and cloning of a Mycoplasma genitalium genome. Science 319(5867): 1215-1220.

Gratz, S.J., A.M. Cummings, J.N. Nguyen, D.C. Hamm, L.K. Donohue, M.M. Harrison, J. Wildonger, and K.M. O'Connor-Giles. 2013. Genome engineering of Drosophila with the CRISPR RNA-guided Cas9 nuclease. Genetics 194(4): 1029-1035.

Harris, J. 2016. Germline modification and the burden of human existence. Cambridge Quarterly of Healthcare Ethics 25(1): 1-13. 
Hosman, E. 2015. Gene therapy: Comeback? Cost-prohibitive? Biopoliticaltimes.org, November 19. http://www.biopoliticaltimes.org/article.php?id=8991. Retrieved November 20, 2015.

Hwang, W.Y., Y. Fu, D. Reyon, M.L. Maeder, S.Q. Tsai, J.D. Sander, R.T. Peterson, J.R.J. Yeh, and J.K. Joung. 2013. Efficient genome editing in zebrafish using a CRISPR-Cas system. Nature Biotechnology 31(3): 227-229.

Ingrassia, P. 2008. This car changed America: A look at Ford's Model T, which debuted 100 years ago. Wall Street Journal, September 27. http://www.wsj.com/articles/SB122246777029780525. Retrieved November 24, 2015.

Jiang, W., D. Bikard, D. Cox, F. Zhang, and L.A. Marraffini. 2013. RNA-guided editing of bacterial genomes using CRISPR-Cas systems. Nature Biotechnology 31(3): 233-239.

Jinek, M., A. East, A. Cheng, S. Lin, E. Ma, and J.A. Doudna. 2013. RNA-programmed genome editing in human cells. Elife 2: e00471.

Kennedy, E.M., and B.R. Cullen. 2015. Bacterial CRISPR/Cas DNA endonucleases: A revolutionary technology that could dramatically impact viral research and treatment. Virology 479: 213-220.

Kline, R., and T. Pinch. 1996. Users as agents of technological change: The social construction of the automobile in the rural United States. Technology and Culture 37(4): 763-795.

Kutter, S. 2015. Gene therapy conquered: The 1-million-euro syringe. Wirtschafts Woche Medicine, April 4. http://www.wiwo.de/technologie/forschung/gen-therapie-erobert-deutschland-die-1-million-eurospritze/11499176-all.html. Retrieved November 4, 2015.

Lanphier, E., F. Urnov, S.E. Haecker, M. Werner, and J. Smolenski. 2015. Don't edit the human germ line. Nature 519(7544): 410-411.

Larson, C. 2015. China's bold push into genetically customized animals. Science American, November 17. http://www.scientificamerican.com/article/china-s-bold-push-into-genetically-customizedanimals/. Retrieved November 20, 2015.

Ledford, H. 2015. CRISPR, the disruptor. Nature 522(7554): 20-24.

Lewis, T. 2015. Chinese scientists want to sell these teensy genetically-engineered pigs as pets. Business Insider, September 30. http://www.businessinsider.com/chinese-genetically-engineered-mini-pigs2015-9. Retrieved November 4, 2015.

Li, D., Z. Qiu, Y. Shao, Y. Chen, Y. Guan, M. Liu, Y. Li, et al. 2013a. Heritable gene targeting in the mouse and rat using a CRISPR-Cas system. Nature Biotechnology 31(8): 681-683.

Li, F.D., Y. Li, H. Liu, H.H. Zhang, C.X. Liu, X.J. Zhang, H.W. Dou, W.X. Yang, and Y.T. Du. 2014. Production of GHR double-allelic knockout Bama pig by TALENs and handmade cloning. Yi Chuan 36(9): 903-911.

Li, J.F., J.E. Norville, J. Aach, M. McCormack, D. Zhang, J. Bush, G.M. Church, and J. Sheen. 2013 b. Multiplex and homologous recombination-mediated genome editing in Arabidopsis and Nicotiana benthamiana using guide RNA and Cas9. Nature Biotechnology 31(8): 688-691.

Li, W., F. Teng, T. Li, and Q. Zhou. 2013c. Simultaneous generation and germline transmission of multiple gene mutations in rat using CRISPR-Cas systems. Nature Biotechnology 31(8): 684-686.

Liang, P., Y. Xu, X. Zhang, C. Ding, R. Huang, Z. Zhang, J. Lv, et al. 2015. CRISPR/Cas9-mediated gene editing in human tripronuclear zygotes. Protein \& Cell 6(5): 363-372.

Mali, P., L. Yang, K.M. Esvelt, J. Aach, M. Guell, J.E. DiCarlo, J.E. Norville, and G.M. Church. 2013. RNA-guided human genome engineering via Cas9. Science 339(6121): 823-826.

Mariscal, C. 2015. Universal biology: Assessing universality from a single example. In The impact of discovering life beyond earth, ed. S. Dick. Cambridge: Cambridge University Press.

Moor, J.H. 2005. Why we need better ethics for emerging technologies. Ethics and Information Technology 7(3): 111-119.

Morange, M. 2015. Genetic modification of the human germ line: The reasons why this project has no future. Comptes Rendus Biologies 338(8): 554-558.

Nekrasov, V., B. Staskawicz, D. Weigel, J.D.C. Jones, and S. Kamoun. 2013. Targeted mutagenesis in the model plant Nicotiana benthamiana using Cas9 RNA-guided endonuclease. Nature Biotechnology 31(8): 691-693.

Nriagu, J.O. 1990. The rise and fall of leaded gasoline. Science of the Total Environment 92: 13-28.

Peng, Z. 2005. Current status of gendicine in China: Recombinant human Ad-p53 agent for treatment of cancers. Human Gene Therapy 16(9): 1016-1027.

Räty, J.K., J.T. Pikkarainen, T. Wirth, and S. Ylä-Herttuala. 2008. Gene therapy: The first approved genebased medicines, molecular mechanisms and clinical indications. Current Molecular Pharmacology 1(1): 13-23. 
Reardon, S. 2015. Leukaemia success heralds wave of gene-editing therapies. Nature News 527(7577): 146-147. http://www.nature.com/news/leukaemia-success-heralds-wave-of-gene-editing-therapies1.18737. Retrieved November 5, 2015.

Sander, J.D., E.J. Dahlborg, M.J. Goodwin, L. Cade, F. Zhang, D. Cifuentes, S.J. Curtin, S.J. Blackburn, S. Thibodeau-Beganny, Y. Qi, C.J. Pierick, E. Hoffman, M.L. Maeder, C. Khayter, D. Reyon, D. Dobbs, D.M. Langenau, R.M. Stupar, A.J. Giraldez, D.F. Voytas, R.T. Peterson, J.R.J. Yeh, and J.K. Joung. 2011. Selection-free zinc-finger-nuclease engineering by context-dependent assembly (CoDA). Nature Methods 8(1): 67-69.

Sherkow, J.S., and H.T. Greely. 2013. What if extinction is not forever? Science 340(6128): 32-33.

Sigma-Aldrich. 2011. Sigma ${ }^{\circledR}$ life science reaches milestone in gene editing with increased affordability for CompoZr ${ }^{\circledR}$ ZFNs and the expansion of knockout ZFNs to include every gene in mice and rats advances in technology platform and new production center result in more content and less expensive Compozr ZFNs. http://investor.sigmaaldrich.com/releasedetail.cfm?ReleaseID=596302. Retrieved November 4, 2015.

Sontheimer, E.J., and R. Barrangou. 2015. The bacterial origins of the CRISPR genome-editing revolution. Human Gene Therapy 26(7): 413-424.

Specter, M. 2015. The gene hackers. The New Yorker, November 16. http://www.newyorker.com/ magazine/2015/11/16/the-gene-hackers. Retrieved November 20, 2015.

Sturgeon, T., and Florida, R. (2000). Globalization and jobs in the automotive industry. Final report to the Alfred P. Sloan Foundation. International Motor Vehicle Program, Center for Technology, Policy, and Industrial Development, Massachusetts Institute of Technology. https://www.creativeclass.com/ rfcgdb/articles/2000-The_World_That_Changed_The_Machine_Globalization_And_Jobs_In_The_ Automotive_Industry.pdf. Retrieved November 5, 2015.

U.S. Food and Drug Administration (FDA). 2015. Cellular and gene therapy products, October 20. http:// www.fda.gov/biologicsbloodvaccines/cellulargenetherapyproducts/default.htm. Retrieved November $4,2015$.

Waltz, E. 2016. Gene-edited CRISPR mushroom escapes US regulation. Nature News 532: 293.

Wang, H., H. Yang, C.S. Shivalila, M.M. Dawlaty, A.W. Cheng, F. Zhang, and R. Jaenisch. 2013. Onestep generation of mice carrying mutations in multiple genes by CRISPR/Cas-mediated genome engineering. Cell 153(4): 910-918.

Williams, K., C. Haslam, and J. Williams. 1992. Ford versus Fordism: The beginning of mass production? Work, Employment \& Society 6(4): 517-555.

Wilson, J.M. 2005. Gendicine: The first commercial gene therapy product; Chinese translation of editorial. Human Gene Therapy 16(9): 1014-1015.

Womack, J.P., D.T. Jones, and D. Roos. 1990. The machine that changed the world. New York: Rawson Associates.

Yang, L., M. Güell, D. Niu, H. George, E. Lesha, D. Grishin, J. Aach, et al. 2015. Genome-wide inactivation of porcine endogenous retroviruses (PERVs). Science 350(6264): 1101-1104.

Yeadon, J. 2015. Pros and cons of ZFNs, TALENs, and CRISPR/Cas. https://www.jax.org/news-andinsights/jax-blog/2014/march/pros-and-cons-of-znfs-talens-and-crispr-cas. Retrieved November 4, 2015.

Zhang, L., and Q. Zhou. 2014. CRISPR/Cas technology: a revolutionary approach for genome engineering. Science China Life Sciences 57(6): 639-640.

Zhou, Q. 2015. Overview of Chinese gene editing research and policy. Question and answer period, information-gathering meeting for the planning committee organizing the international summit on human gene editing, October 5, Washington, DC.

Zimmer, C. 2013. Bringing them back to life. National Geographic 223(4): 28. 